\begin{tabular}{cc|c}
\hline Tar. Bil. Der. & Journal of Agricultural Sciences \\
& $\begin{array}{c}\text { Dergi web sayfası: } \\
\text { www.agri.ankara.edu.tr/dergi }\end{array}$ & Journal homepage: \\
& www.agri.ankara.edu.tr/journal
\end{tabular}

\title{
Gentiana olivieri Griseb.’in Kallus Kültürlerinin Kurulması ve Sekonder Metabolitlerin Araştırılması
}

\author{
Canan YAĞCI TÜZÜN ${ }^{a}$, Mehmet CİHAT TOKER ${ }^{a}$, Gülnur TOKER ${ }^{b}$ \\ a Ankara Üniversitesi, Fen Fakültesi, Biyoloji Bölümü, Tandoğan, Ankara, TÜRKIYYE \\ ${ }^{\boldsymbol{b}}$ Gazi Üniversitesi, Eczacıllk Fakültesi, Farmakognozi Anabilim Dalı, 06330, Etiler, Ankara, TÜRKIYE
}

\section{ESER BILLİSI}

Araştırma Makalesi — Bitkisel Üretim ～https://doi.org/10.1501/Tarimbil_0000001241

Sorumlu Yazar: Canan YAĞCI TÜZÜN, E-posta: yagcicanan@gmail.com, Tel: +90 (312) 3431050 / 1397

Geliş Tarihi: 8 Ekim 2009, Düzeltmelerin Gelişi: 17 Haziran 2013, Kabul: 17 Haziran 2013

\section{ÖZET}

Gaziantep yöresinde Afat olarak bilinen Gentiana olivieri'nin herbası, halk arasında iştah açıcı, sindirime yardımcı, antidiyabetik, antianemik, antihepatotoksik ve sakinleştirici olarak kullanılmaktadır. Bu çalışmada, in vitro çimlendirilen G. olivieri'den alınan kök ve yaprak eksplantlarının karanlıkta kallus üretim kapasitesi araştırılmıştır. WPM ve MS ortamlarına kallus dokusu oluşumunu uyarmak için $0.5 \mathrm{mg} \mathrm{L}^{-1} \mathrm{BAP}-1 \mathrm{mg} \mathrm{L} \mathrm{L}^{-1} \mathrm{NAA}$ ile 0.2 ve $0.5 \mathrm{mg} \mathrm{L} \mathrm{K}^{-1} \mathrm{Kinetin}^{-}$ - 1 mg L L NAA kullanılmıştır. Kalluslar her 4 haftada bir alt kültüre alınmıștır. Kallus miktarındaki artışı belirlemek için kallus büyüme indeksi hesaplanmıştır. En iyi kallus gelişimi yaprak eksplantında, $0.5 \mathrm{mg} \mathrm{L}^{-1} \mathrm{BAP}-1 \mathrm{mg} \mathrm{L}^{-1} \mathrm{NAA}_{\text {içeren }}$ WPM'de eksplant ekimini takiben 4 hafta sonra gözlenirken, kök eksplantında ise $0.2 \mathrm{mg} \mathrm{L}^{-1}$ Kinetin- $1 \mathrm{mg} \mathrm{L}^{-1} \mathrm{NAA}^{-1}$ içeren MS ortamında, 8 hafta sonra gözlenmiştir. Yaprak eksplantından WPM'de üç alt kültür süresince oluşan kalluslar, metanol ile ekstre edilmiştir. Sekonder metabolitler ince tabaka kromatografisiyle (İTK) incelenmiştir. Plaklarda, iridoit yapısında olduğu düşünülen lekeler gözlenmiştir.

Anahtar Kelimeler: Gentiana olivieri; Kallus kültürü; Kallus büyüme indeksi; Sekonder metabolit üretimi

\section{Establishment of Callus Cultures of Gentiana olivieri Griseb. and Investigation of Secondary Metabolites}

\section{ARTICLE INFO}

Research Article - Crop Production

Corresponding Author: Canan YAĞCI TÜZÜN, E-mail: yagcicanan@gmail.com, Tel: +90 (312) 3431050 / 1397

Received: 8 October 2009, Received in Revised Form: 17 June 2013, Accepted: 17 June 2013

\section{ABSTRACT}

Flowered herba of Gentiana olivieri which is known as Afat in Gaziantep region is used in traditional folk medicine as appetizer, digestive aid, antidiabetic, antianemic, antihepatotoxic and antidepressant. In this study, callus production capacity of root and leaf explants obtained from in vitro germinated seeds of G. olivieri were investigated in dark. 
WPM or MS medium containing $0.5 \mathrm{mg} \mathrm{L} \mathrm{L}^{-1} \mathrm{BAP}-1 \mathrm{mg} \mathrm{L}{ }^{-1} \mathrm{NAA}$ or 0.2 and $0.5 \mathrm{mg} \mathrm{L}^{-1}$ Kinetin- $1 \mathrm{mg} \mathrm{L} \mathrm{L}^{-1}$ NAA were used for stimulating the induction of callus tissue. The calli were subcultured every 4 weeks. Callus growth index was calculated for determination of increasing the callus quantity. The best callus growths were observed in leaf explants formed on WPM containing $0.5 \mathrm{mg} \mathrm{L}^{-1} \mathrm{BAP}-1 \mathrm{mg} \mathrm{L}^{-1} \mathrm{NAA}$ after 4 weeks followed by explants sowing and in root explants formed on MS medium containing $0.2 \mathrm{mg} \mathrm{L}^{-1}$ Kinetin - $1 \mathrm{mg} \mathrm{L}^{-1} \mathrm{NAA}$ after 8 weeks of culture. Calli which were induced on leaf explants grown on WPM during three subcultures were extracted with methanol. Secondary metabolites were investigated by thin layer chromatography (TLC). Spots, which were expected to have iridoidal structure, were observed on TLC plates.

Keywords: Gentiana olivieri; Callus culture; Callus growth index; Secondary metabolite production

(C) Ankara Üniversitesi Ziraat Fakültesi

\section{Giriş}

Gentiana olivieri Griseb. (Gentianaceae) 350-2300 m yükseklikte, killi, kireçli, marnlı topraklarda ve nemli otlaklarda yetişen çok yıllık otsu bir bitkidir (Pritchard 1978). Gaziantep yöresinde Afat olarak bilinen bitkinin çiçekli toprak üstü kısımları halk arasında kan şekerini düzenleyici, yara iyileştirici, antianemik, antihepatotoksik, sakinleştirici ve iştah açıcı olarak kullanılmaktadır (Baytop 1984; Başer et al 1986; Ersöz \& Çalış 1991; Deliorman Orhan et al 2003; Sezik et al 2005). Yapılan araştırmalarda G. olivieri'nin metanollü ekstresinin yüksek antidiyabetik özellik gösterdiği ve bu özelliğin de bir flavonoit olan izoorientinden kaynaklandığ bulunmuştur (Aslan 2000). Yapılan çok sayıda çalışma sonucunda Gentianaceae familyasına dahil bitkilerde iştah açıcı ve sindirime yardımcı olduğu bilinen iridoit ve sekoiridoitler; antidiyabetik, antihepatotoksik, antianemik özellikleri bulunan flavonoitler ile antihipertansif özelliği bulunan alkaloitler saptanmıştır. (Tan et al 1998; Mansoor et al 2004). Bu özellikler seneler önce fark edilerek özellikle Çin geleneksel tedavi sisteminde kullanıldığı bilinmektedir (Yang 2001).

İçerdikleri ilaç hammaddelerinin yanında gösterişli çiçeklere sahip olan ve Gentian genel ismiyle anılan bu bitkiler, Avrupa ve Uzakdoğu ülkeleri başta olmak üzere birçok ülkede saksı çiçeği ve kesme çiçek olarak da tüketilmektedir. Tüm bu kullanım alanları nedeniyle bazı Gentian'ların nesli tükenme tehlikesiyle karşı karşıya kalmış ve korumaya alınmıştır. Türkiye'de de G. lutea, 2008 yılından itibaren toplanması ve ihracatı yasaklanan
20 bitki türü içinde yer almaktadır (RG 2013). Gentianlar üzerinde in vitro organogenez (ButiucKeul et al 2005); somatik embriyogenez (Bach \& Pawlowska 2003; Fiuk \& Rybczynski 2008); kallus (Morgan et al 1997; Momcilovic et al 1997), hücre süspansiyon (Chueh et al 2000) ve protoplast kültürü (Meng et al 1996) ile rejenerasyon ve mikroçoğaltım vb. çalışmalar yapılmıştır.

$\mathrm{Bu}$ çalışmanın amacı, G. olivieri'den alınan kök ve yaprak eksplantlarının farklı besin ortamı ve büyüme düzenleyicilerinin etkisi ile kallus oluşturabilme kapasitesini gözlemlemek ve elde edilen kalluslarda üretilen sekonder metabolitleri ince tabaka kromatografisiyle (İTK) araştırmaktır.

\section{Materyal ve Yöntem}

Çalışmada kullanılan G. olivieri tohumları Gaziantep açık piyasadan satılan kurutulmuş bitkilerden alınmıştır. Bitkinin teşhisi Ankara Üniversitesi Herbaryumu'nda yapılmış ve bir örnek Herbaryum'a verilmiştir (08CYT01). Tohumlar in vitro koşullarda çimlendirilmiş ve elde edilen fideciklerden alınan kök ve yaprak eksplantları kullanılmıştır.

\subsection{In vitro çimlendirme}

In vitro çimlendirme için $10 \mathrm{mg} \mathrm{L}^{-1}$ myo-inositol, $0.04 \mathrm{mg} \mathrm{L}^{-1}$ tiyamin $\mathrm{HCl}, 30 \mathrm{~g} \mathrm{~L}^{-1}$ sükroz ve $8 \mathrm{~g} \mathrm{~L}^{-1}$ agar içeren MS (Murashige \& Skoog 1962) besin ortamı kullanılmıştır. Çimlenmeyi teşvik için MS ortamına $0.2 \mathrm{mM} \mathrm{GA}_{3}$ eklenmiştir. Ekilen tohumlar 3000 lux 1şık şiddetinde $24-25^{\circ} \mathrm{C}$ 'de 8 hafta inkübe edilmiştir (Momcilovic et al 1997; Yağcı 2005). 


\subsection{Kallus kültürü}

In vitro çimlendirilen fidelerden kök ve yaprak eksplantları alınarak kallus geliştirme ortamlarında kültüre alınmıştır. Kallus üretme çalışmaları için in vitro çimlenmede kullanılan MS ortamı ile 100 $\mathrm{mg} \mathrm{L} \mathrm{L}^{-1}$ myo-inositol, $0.5 \mathrm{mg} \mathrm{\textrm {L } ^ { - 1 }}$ piridoksin $\mathrm{HCl}$, $2 \mathrm{mg} \mathrm{L}^{-1}$ glisin, $20 \mathrm{~g} \mathrm{~L}^{-1}$ sükroz ve $8 \mathrm{~g} \mathrm{~L}^{-1}$ agar içeren Woody Plant Medium-WPM (Lloyd \& McCown 1980) besin ortamı kullanılmıştır. Bu ortamlara NAA, BAP ve Kinetin büyüme düzenleyicileri eklenmiştir (Çizelge 1).

Çalışmada kullanılan tüm büyüme düzenleyiciler otoklavdan önce eklenmiştir. $1 \mathrm{M} \mathrm{HCl} / 1 \mathrm{M} \mathrm{NaOH}$ ile $\mathrm{pH}, 5.8^{\prime} \mathrm{e}$ ayarlanmış ve ortamlar $121^{\circ} \mathrm{C}$ 'de $15 \mathrm{dk}$. steril edilmiştir. $10 \mathrm{~cm}$ çapında cam petrilere yapraktan 5-6, kökten ise 5 adet eksplant ekilmiştir. İnkübasyon karanlıkta ve $24-25^{\circ} \mathrm{C}$ 'de gerçekleştirilmiştir.

Eksplant kültürü (ilk 4 hafta) ve kallus oluşumu aşaması (ikinci 4 hafta) sonrasında gelişimlerine devam eden kalluslar, her 4 haftada bir aynı içeriğe sahip taze ortamlara aktarılarak alt kültüre alınmıştır. Bu şekilde ilk kallus kültürü denemesinde kök ve yaprak eksplantından oluşan kalluslar 3 alt kültür boyunca izlenmiştir. Her alt kültüre aktarım aşamasında kallusların ağırlıkları tartılmış ve bir miktar kallus ayrıca tartılarak analiz için derin dondurucuya alınmıştır. Kallusların yaş ağırlıklarına göre gelişiminin izlenmesi için kallus büyüme indeksi (KBİ) hesaplanmıştır (Memişoğlu 2005). Deneyler üç tekrarlı tasarlanmıştır.

\subsection{Kallusların ekstraksiyonu ve kromatografik analiz (ITK)}

1., 2. ve 3. alt kültür sonunda elde edilen kalluslar, yapısındaki sekonder metabolitlerin bozulmaması için analiz edilene kadar $-20^{\circ} \mathrm{C}$ 'de dondurulmuştur. Derin dondurucundan alınan kalluslar, liyofilizatörde kurutulmuştur. Kurutulan ve ezilerek toz haline getirilen kalluslar $(0.1 \mathrm{~g}), \% 80$ 'lik metanol ile 10 dakika ultrasonik banyoda, ardından 1 saat $50^{\circ} \mathrm{C}^{\prime}$ lik su banyosunda ve tekrar 10 dakika ultrasonik banyoda bekletilip süzülerek ekstreler hazırlanmıştır.

Çizelge 1- MS ve WPM ortamlarına ekilen yaprak (Y) ve kök (K) eksplantlarının Kallus Büyüme İndeksleri (KBi)

Table 1- Callus Growth Index of leaf and root explants which were sown on MS and WPM media

\begin{tabular}{|c|c|c|c|c|c|c|c|c|}
\hline \multirow{2}{*}{ Ortamlar } & \multirow{2}{*}{ Eksplant tipi } & \multicolumn{3}{|c|}{ Büyüme düzenleyiciler $\left(m g L^{-1}\right)$} & \multicolumn{4}{|c|}{ Kallus büyüme indeksi (KBİ) } \\
\hline & & $N A A$ & $B A P$ & Kinetin & $K$ & $1^{a}$ & $2^{b}$ & $3^{c}$ \\
\hline MS1Y* & Yaprak & 1 & 0.5 & - & 38.63 & 3.09 & 1.88 & 2.38 \\
\hline MS2Y & Yaprak & 1 & - & 0.5 & 39.58 & 3.86 & 2.06 & 2.4 \\
\hline MS3Y & Yaprak & 1 & - & 0.2 & 46.25 & 3.22 & 2.33 & 2.49 \\
\hline WPM1Y & Yaprak & 1 & 0.5 & - & 59.52 & 11.9 & 1.73 & 1.71 \\
\hline WPM2Y & Yaprak & 1 & - & 0.5 & 48.51 & 5.67 & 2.18 & 2.34 \\
\hline WPM3Y & Yaprak & 1 & - & 0.2 & 48.21 & 3.27 & 1.81 & 2.27 \\
\hline MS1K & Kök & 1 & 0.5 & - & 7.7 & 14.78 & 2.58 & 1.82 \\
\hline MS2K & Kök & 1 & - & 0.5 & 4.15 & 16.17 & 3.23 & 2.2 \\
\hline MS3K & Kök & 1 & - & 0.2 & 8.51 & 17 & 2.41 & 2.67 \\
\hline WPM1K & Kök & 1 & 0.5 & - & 6.14 & 4.36 & 3.37 & 3.77 \\
\hline WPM2K & Kök & 1 & - & 0.5 & 7.35 & 4.09 & 2.24 & 1.94 \\
\hline WPM3K & Kök & 1 & - & 0.2 & 6.89 & 8.71 & 3.28 & 2.36 \\
\hline
\end{tabular}

*, $1 \mathrm{mg} \mathrm{L}{ }^{-1}$ NAA ve $0.5 \mathrm{mg} \mathrm{L}^{-1}$ BAP içeren MS ortamında yaprak eksplantı

K, Kallus oluşumu (ilk 4 hafta); $1^{\text {a }}$, birinci alt kültür; $2^{\text {b }}$, ikinci alt kültür; $3^{\mathrm{c}}$, üçüncü alt kültür. 
G. olivieri herba ekstresi de aynı yöntemle hazırlanmıştır. $\mathrm{Bu}$ ekstreler flavonoit yapısındaki izoorientin, izoviteksin ve viteksin standartları ile birlikte İTK'ya uygulanmıştır. İTK'da Silikagel 60 plaklar (Merck, Germany) ile Etil asetat: Formik asit: Asetik Asit: Su (100:11:11:27) solvan sistemi kullanılmıştır. Revelatör olarak plaklara flavonoitler için Naturstoff reaktifi (NA) ve iridoitler için \% 30 'luk $\mathrm{H}_{2} \mathrm{SO}_{4}$ püskürtülüp $100^{\circ} \mathrm{C}^{\prime}$ de 5 dk. bekletilmiştir. Lekeler $\mathrm{UV}_{366}$ ve günışı̆̆ında gözlenerek değerlendirilmiştir.

\section{Bulgular ve Tartışma}

\subsection{Kallus kültürü}

Çalışmamızda G. olivieri tohumlarının in vitro çimlendirilmesi ile elde edilen kök ve yaprak eksplantlarında kallus oluşumunun en iyi olduğu ortam, büyüme düzenleyicisi ve kallus büyüme indeksi (KBİ) (Çizelge 1) belirlenmiştir. Yaprak eksplantının cevabı her iki ortam tipi için ilk 4 haftalık periyotta (kallus oluşum aşaması) hem kallus artışı hem de büyüme hızı bakımından kök eksplantına göre daha iyi bulunmuştur. Buna karşılık kök eksplantından oluşan kallusların miktarı ve büyüme hızları, 1. alt kültür sonunda (ekimden 8 hafta sonra) artışa geçmiştir. Yaprak eksplantında 1. alt kültür, kök eksplantında ise 2. alt kültürden sonra kallus artışı ve büyüme hızları genellikle düşüşe geçmiş veya sabit kalmıştır (Çizelge 1).

Kallus artışının en yüksek olduğu kallus oluşumu aşamasında, yaprak eksplantından elde edilen kalluslarda, WPM ortamının MS ortamına göre daha başarılı olduğu gözlenmiştir. Buna karşın kök eksplantından oluşan kalluslarda, 1. alt kültürden sonra MS ortamının WPM ortamına göre daha iyi sonuç verdiği bulunmuştur (Çizelge 1).

Bu çalışma ile toprak üstü (yaprak) ve toprak altı (kök) eksplantlarının sabit konsantrasyonda oksin (NAA) ve değişken konsantrasyonda sitokinin (BAP ve Kinetin) içeren iki farklı ortama verdikleri tepkiler araştırılmıştır. Sitokininler ve konsantrasyonları kallus artışını da etkilemiştir. $0.5 \mathrm{mg} \mathrm{L}^{-1} \mathrm{BAP}$ içeren
WPM1 ortamında, ilk 4 haftada yapraktan gelişen kallus dokusu, çalışmamızda doku kültürüne en hizlı cevap veren ortam olmuştur. MS1 ve WPM1 ortamlarında, yapraklardan gelişen kallus dokusu artışında oldukça önemli bir fark vardır (KBİ: 38.63 ve 59.52). MS ve WPM ortamlarında ilk 4 haftada gelişen kallusların artışına bakıldığında, WPM'nin kallus gelişiminde MS ortamına göre daha başarılı görülmektedir. Kinetin kullanılan MS2 ve WPM2 ortamlarında ise yaprak eksplantında WPM2 daha başarılı olmuştur (KBİ: 48.51). MS3 ve WPM3 ortamlarında kallus büyüme indeksleri arasında fark görülmemiştir (Çizelge 1).

MS ortamlarında, kökten elde edilen kalluslarda, kallus oluşumu aşamasına göre 1 . alt kültürde 2 ila 3.9 kat artış sağlamış ardından düşüş olmuştur. WPM'de ise kallus büyüme indeksi ilk 4 haftadan sonraki alt kültürlerde biraz düşmüş ve sabit kalmıştır (Çizelge 1).

\subsection{Kromatografik analiz (ITK)}

Önceki çalışmalarda G. olivieri herbasında flavonoitlerin varlığı tespit edilmiştir (Aslan 2000; Edis 2003). Çalışmamızda elde edilen kallusların İTK's1 sonucu, karanlıkta gelişen kalluslarda flavonoit grubundan olan izoorientin, izoviteksin ve viteksin tespit edilmemiştir. Plaklara $\mathrm{H}_{2} \mathrm{SO}_{4}$ çözeltisi püskürtülünce meydana gelen kahve-viyole renkli lekelerden dolayı iridoit ve sekoiridoit yapılı bileşiklerin üretildiği düşünülmektedir (Şekil 1 ve 2). Özellikle WPM2 ortamında gelişen kalluslarda üretilen sekonder metabolit miktarının (lekelerin koyuluğu) daha fazla olduğu gözlenmiştir (Şekil 1 ve 2).

Gentianaceae familyasındaki türler üzerinde doku kültürü yöntemleri kullanılarak genellikle sekoiridoitler üretilmektedir. Menkovic et al (2000a), in vitro kültür ile elde edilen G. lutea'nın gövde, kök ve saçak köklerindeki sekoiridoit ve $\gamma$-piron bileşiklerin kantitatif belirlenmesi için çalışma yapmışlardır. Chueh et al (2000) Çin halk tıbbında $G$. davidii var. formosana'dan elde edilen ve Long-Dan adiyla kullanılan ilacin etken maddeleri olan gentiopikrozit ve svertiamarinin büyük ölçülerde üretilebilmesi, bu sayede bitkinin 


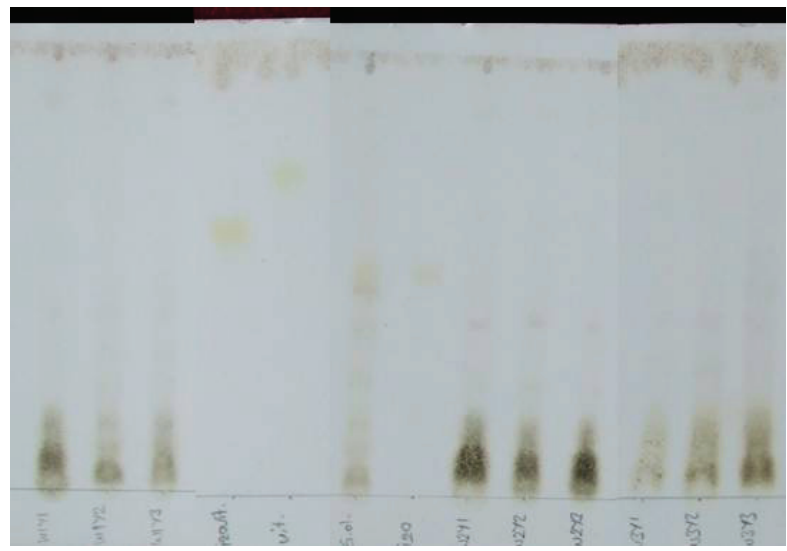

Şekil 1- WPM ortamında gelişen yaprak kaynaklı kalluslardan elde edilen ekstrelerin, gün ışı̆̆ında görüntülenen İTK kromatogramı (Plaklara $\mathrm{H}_{2} \mathrm{SO}_{4}$ püskürtülmüsştür) (tatbikler soldan sağa sırasıyla W1Y1-W1Y2-W1Y3- izoviteksin-viteksin-G. olivieri herba ekstresi-izoorientin W2Y1-W2Y2-W2Y3W3Y1-W3Y2-W3Y3. Örnek kodlama; W1Y1- WPM1 ortamında 1. alt kültürde gelişen yaprak kaynaklı kalluslar)

Figure 1- TLC chromatogram of extracts obtained from leaf derived callus grown on WPM medium, viewed in daylight $\left(\mathrm{H}_{2} \mathrm{SO}_{4}\right.$ was sprayed on TLC plates) (The order of application is left to the right; W1Y1-W1Y2-W1Y3isovitexin-vitexin-G. olivieri herba extract- isoorientin-W2Y1-W2Y2-W2Y3-W3Y1-W3Y2-W3Y3. Sample coding; W1Y1-Leaf derived calli grown on WPM1 medium in the first sub-culture)

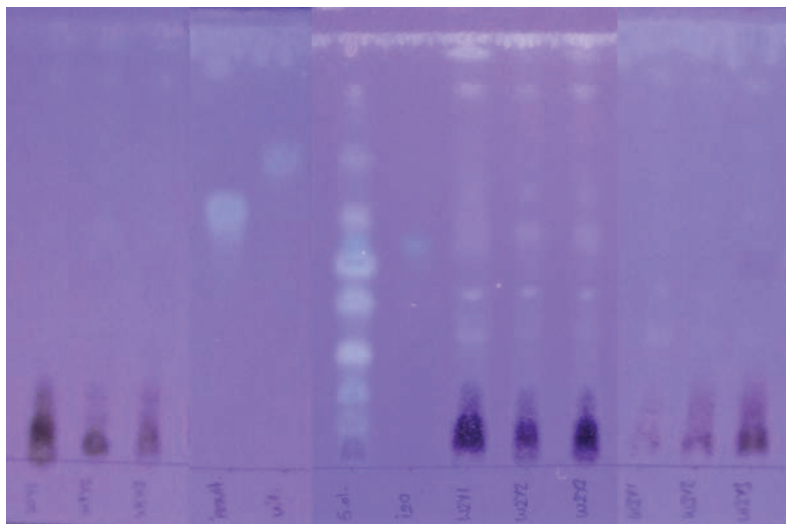

Şekil 2- WPM ortamında gelişen yaprak kaynaklı kalluslardan elde edilen ekstrelerin, UV , $^{\text {'da }}$ görüntülenen ITK kromatogramı (Plaklara $\mathrm{H}_{2} \mathrm{SO}_{4}$ püskürtülmüştür) (Tatbikler soldan sağa sırasıyla W1Y1-W1Y2-W1Y3-izoviteksin-viteksin-G. olivieri herba ekstresi-izoorientin-W2Y1-W2Y2-W2Y3W3Y1-W3Y2-W3Y3. Örnek kodlama; W1Y1- WPM1 ortamında 1. alt kültürde gelişen yaprak kaynaklı kalluslar)

Figure 2- TLC chromatogram of extracts obtained from leaf derived callus grown on WPM medium, viewed in $\mathrm{UV}_{366}\left(\mathrm{H}_{2} \mathrm{SO}_{4}\right.$ was sprayed on TLC plates) (The order of application is left to the right; W1Y1-W1Y2-W1Y3isovitexin-vitexin-G. olivieri herba extract-W2Y1-W2Y2-W2Y3-W3Y1-W3Y2-W3Y3. Sample coding; W1Y1-Leaf derived calli grown on WPM1 medium in the first sub-culture) 
doğal yaşamının korunması amaciyla süspansiyon kültürü yapmışlardır. Devic et al (2006), yaptıkları çalışmada $G$. asclepiadea'yı in vitro çoğaltmışlar ve elde ettikleri bitkilerdeki ksanton yapısındaki mangiferin ve sekoiridoit yapısındaki gentiopikrozit miktarını belirlemişlerdir. Buna göre kültüre alınan bitkilerde sitokininlerin varlığında mangiferin ve gentiopikrin birikiminin doğal gelişen bitkilere göre dikkate değer biçimde uyarıldığını gözlemişırerdir.

\section{Sonuçlar}

Çalışmamızda yaprak eksplantında en fazla kallus artışı, ilk 4 haftalık periyotta $1 \mathrm{mg} \mathrm{L}{ }^{-1} \mathrm{NAA}$ ve 0.5 BAP içeren WPM ortamında (WPM1) gözlenmiştir. Kök eksplantında ise eksplant ekimini takiben 8 hafta sonra yani 1. alt kültürde MS ortamlarında kallus artışları fazla bulunmuştur (Çizelge 1). Bu sonuçlara göre WPM ortamı, yaprak eksplantında kallus oluşumunu daha çok uyarırken kök eksplantından kallus oluşumunda MS ortamı daha etkili olmuştur. İTK'da oluşan lekelere göre, karanlıkta inkübe edilen kalluslarda flavonoit yapısında maddeler yerine, iridoit karakterindeki maddelerin üretildiği düşünülmektedir.

Flavonoit yapısındaki maddelerin genellikle topraküstü organlarda daha çok bulunması nedeniyle flavonoit üretimi için yapılacak ileri çalışmalarda inkübasyonun aydınlıkta yapılması önerilebilir. İridoit ve sekoiridot yapısındaki maddelerin iştah açıcı ve mide rahatsızlıklarını azaltıcı etkilerinden dolayı bu maddelerin üretimi ve artırılması yönünde çalışmalar da yapılabilir (Menkovic et al 2000a; Chueh et al 2000; Devic et al 2006).

\section{Kaynaklar}

Aslan M (2000). Şeker Hastalığına Karşı Halk İlacı Olarak Kullanılan Bitkiler Üzerinde Farmakognozik Araştırmalar. Doktora Tezi, Gazi Üniversitesi Sağlık Bilimleri Enstitüsü (Basılmamış), Ankara

Bach A \& Pawlowska B (2003). Somatic Embryogenesis in Gentiana pneumonanthe L. Acta Biologica Cracoviensia 45 (2): 79-86
Başer K H C, Honda G \& Miki W (1986). Herb Drugs and Herbalists in Turkey, Studia Culturae Islamicae 27, Tokyo

Baytop T (1984). Türkiyede Bitkiler ile Tedavi. İstanbul Üniversitesi Yayınları No: 3255, İstanbul, s.194-195

Butiuc-Keul A, Şuteu A \& Deliu C (2005). In vitro Organogenesis of Gentiana punctata. Notulae Botanicae Horti Agrobotanici 33 (1): 38-41

Chueh F, Chen C \& Tsay H (2000). Studies on Factors Affecting the Establisment of Gentiana davidii var. formosana (Hayata) T.N. Ho Cell Suspension Cultures. Journal of Food and Drug Analysis 8 (4): 297-303

Deliorman Orhan D, Aslan M, Aktay G, Ergun E, Yesilada E \& Ergun F (2003). Evaluation of Hepatoprotective Effect of Gentiana olivieri Herbs on Subacute Administration and Isolation of Active Principle. Life Sciences 72: 2273-2283

Devic M, Momcilovic I, Krstic D, Maksimovic V \& Konjevic R (2006). In vitro Multiplication of Willow Gentian (Gentiana asclepiadea L.) and the Production of Gentiopicrine and Mangiferin. Phyton 46 (1): 4554

Edis M (2003). Türkiye'de Yetişen Bazı Gentiana L. Türlerinin İzoorientin Yönünden Değerlendirilmesi. Yüksek Lisans Tezi, Gazi Üniversitesi Sağl1k Bilimleri Enstitüsü (Basılmamış), Ankara

Ersöz T \& Çalış İ (1991). C-Glucosylflavones from Gentiana olivieri. Hacettepe University, Journal of Faculty of Pharmacy 11 (1): 29-36

Fiuk A \& Rybczynski J J (2008). Genotype and Plant Growth Regulator-dependent Response of Somatic Embryogenesis from Gentiana spp. Leaf Explants. In Vitro Cellular and Developmental Biology-Plant 44: 90-99

Lloyd G \& McCown B H (1980). Commercially Feasible Micropropagation of the Mountain Laurel, Kalmia latifolia Linn. by Using Shoot-tip Culture. Combined Proceedings International Plant Propagators'Society 30: $421-427$

Mansoor A, Zaidi M I, Hyder M \& Rasheed R (2004). Antihypertensive Effect of Gentiana olivieri. Journal of Medical Sciences 4 (3): 176-178

Memişoğlu M (2005). Ecballium elaterium Bitkisinde Hücre Süspansiyon Kültürü Tekniği ile Sekonder Metabolit (Kukurbitasin B) Üretimi. Doktora Tezi, Gazi Üniversitesi Sağlık Bilimleri Enstitüsü (Basılmamış), Ankara 
Meng Y, Gao Y \& Jia J (1996). Plant Regeneration from Protoplasts Isolated from Callus of Gentiana crassicaulis. Plant Cell Reports 16: 88-91

Menkovic N, Savikin-Fodulovic K, Momcilovic I \& Grubisic D (2000 a). Quantitative Determination of Secoiridoid and $\gamma$-Pyrone Compounds in Gentiana lutea Cultured in vitro. Planta Medica 66: 96-98

Morgan E R, Butler R M \& Bicknell R A (1997). In vitro Propagation of Gentiana cerina and Gentiana corymbifera. New Zealand Journal of Crop and Horticultural Science 25: 1-8

Momcilovic I, Grubisic D \& Neskovic M (1997). Micropropagation of Four Gentiana species ( $G$. lutea, G. cruciata, G. purpurea and G. acaulis). Plant Cell, Tissue and Organ Culture 49:141-144

Murashige T \& Skoog F (1962). A revised medium for rapid growth and bioassays with tobacco tissue cultures. Physiology Plantarum 15: 473-497

Pawlowska B\& Bach A (2003). In vitro Propagation of Protected Species Gentiana pneumonanthe L. for Ornamental Horticultural Use. Folia Horticulturae 15 (1): 113-122
Pritchard N M (1978). Gentiana L. In: H. Davis (Ed.), Flora of Turkey and East Eagean Islands, vol 6, Edinburgh University Press, Edinburgh, pp. 183-190

R G (2013). Doğal Çiçek Soğanlarının 2013 Yılı İhracat Listesi Hakkında Tebliğ. http://www.resmigazete. gov.tr/eskiler/2012/12/20121206-16.htm (Erişim tarihi:2013)

Tan R X, Kong L D \& Wei H X (1998). Secoiridiod Glycosides and An Antifungal Anthranilate Derivative from Gentiana tibetica. Phytochemistry 47: 12231226

Sezik E, Aslan M, Yesilada E \& Ito S (2005). Hypogylcaemic Activity of Gentiana olivieri and Isolation of the Active Constituent through Bioassaydirected Fractionation Techniques. Life Sciences 76: 1223-1238

Yağcı C (2005). Gentiana olivieri Griseb. (Afat)'nin Bitki Doku Kültürüne Cevabı. Yüksek Lisans Tezi, Ankara Üniversitesi Fen Bilimleri Enstitisü (Basılmamış), Ankara

Yang Y (2001). Chinese Herbal Medicines Comparisons and Characteristics. Elsevier Health Sciences, China, pp.41-63 